\title{
Tubularized Incised Plate (TIP) Urethroplasty in Narrow V/S Wide Urethral Plate: A Comparative Study in a Developing Country Perspective
}

\author{
Adnan Walid, Md. Minhajuddin Sajid, Rajib Khastagir, Tanvir Kabir Chowdhury*, Md. \\ Khurshid Alam Sarwar, Md. Abdullah Al Farooq, Md. Sharif Imam and Mohammad Zonaid \\ Chowdhury
}

Department of Pediatric Surgery, Chittagong Medical College and Hospital, Bangladesh

\begin{abstract}
Introduction: Tubularized incised plate (TIP) urethroplasty is the most commonly performed operation for distal and mid shaft hypospadias. There are controversies in the previous reports regarding the association between urethral plate width and complications in TIP repair. The aim of this study was to compare the impact of urethral plate width in TIP repair on the development of complications in the perspective of a developing country.

Methods: It was a prospective comparative study carried out in the department of pediatric surgery, Chittagong Medical College Hospital, Bangladesh from December, 2017 to March, 2019. Patients with distal and midshaft hypospadias were divided into 2 groups: Group A-urethral plate less than $8 \mathrm{~mm}$ wide and Group B-urethral plate $8 \mathrm{~mm}$ or more wide. Age at surgery, penile characteristics, pre-incision urethral plate width, per-operative factors and development of complications were analyzed. Follow up period ranged from 6 months to 2.5 years.
\end{abstract}

Results: A total of 43 patients ( 21 in group A, 22 in group B), with a mean age of $6.67 \pm 3.38$ years underwent TIP repair. Twenty-five (58\%) patients had distal penile and $18(42 \%)$ had mid shaft hypospadias. Age correlated with glans size and urethral plate width $(\mathrm{P}=0.019$ and 0.003 , respectively) but there was no significant difference in age between patients with or without development of complications $(P=0.71)$. Complications developed in $18(41.87 \%)$ patients, 9 in each group. Mean urethral plate width was $7.37 \pm 0.84 \mathrm{~mm}$ and $7.19 \pm 1.17 \mathrm{~mm}$ in patients who had successful repair and those developed complications, respectively $(P=0.59)$. Duration of tourniquet, size of catheter, layers of repair, duration of dressing or catheter were not also associated with UC fistula, the most common complication $(P=0.26,0.58,0.76$, 0.38 , and 0.56 , respectively).

Conclusion: Width of urethral plated was not related to development of complications in TIP repair. Complication rates were high in comparison to other studies and skill development and improvement of other factors are necessary in the developing world to improve outcome.

Keywords

Hypospadias, Urethral plate width, Tabularised incised plate urethroplasty, Urethrocutaneous Fistula

\section{Introduction}

Tubularized incised plate (TIP) urethroplasty has become an attractive method worldwide for hypospadias repair since its introduction in 1994 for distal hypospadias and 1998 for mid shaft and proximal hypospadias [1]. Although reports from developed world show excellent outcome of this procedure, the descriptions from many developing countries still show more fistula rates and other complications [2-6]. Moreover, there is still debate about the ultimate outcome of incising a urethral plate and the application of TIP where the urethral plate is narrow. There has been concern among surgeons that metal stenosis and urethra-cutaneous (UC) fis-
*Corresponding author: Tanvir Kabir Chowdhury, Department of Pediatric Surgery, Chittagong Medical College and Hospital, Bangladesh, 1, KB Fazlul Kader road, Chattogram 4203, Bangladesh

Accepted: February 13, 2021

Published online: February 15, 2021

Citation: Walid A, Sajid MM, Khastagir R, et al. (2021) Tubularized Incised Plate (TIP) Urethroplasty in Narrow V/S Wide Urethral Plate: A Comparative Study in a Developing Country Perspective . Arch of Pedia Surg 5(1):80-86 
tula in TIP urethroplasty is more related to the width of the plates than other factors and some surgeons still prefer other methods such as combining with a Mathieu procedure or other modifications for narrow urethral plate [7-9]. This article addressed the issue of urethral plate in TIP urethroplasty for distal and mid shaft hypospadias from the perspective of a tertiary paediatric surgical center from a developing country.

\section{Method}

\section{Type of study}

Hospital based prospective comparative study.

\section{Study period}

December, 2017 to March, 2019.

\section{Place of study}

Department of Paediatric Surgery, Chittagong Medical College Hospital.

\section{Study sample}

All patients below 12 years of age with distal and mid penile hypospadias who were admitted during the study period and fulfilled the selection criteria.

\section{Sampling technique}

Consecutive sampling.

\section{Exclusion Criteria}

Patients with more than $30^{\circ}$ chordee, presence of other urogenital anomaly, hemophilia or bleeding diathesis, previous history of hypospadias repair or circumcision and patients with proximal hypospadias were excluded. Patients who did not comply with at least 2 follow-ups were also excluded.

\section{Group allocation:}

Group A: Urethral plate width $<8 \mathrm{~mm}$ (Narrow urethral plate)

Group B: Urethral plate width $8 \mathrm{~mm}$ or more (Wide urethral plate)

\section{Study Procedure}

Glans width, glans configuration, pre-incision urethral plate width, duration of tourniquets, catheter size, layers of repair were recorded during surgery. A ruler was used to measure stretched penile length and urethral plate width, slide calipers for glans width and protractors for chordee and a goniometer was used for measuring the degree of chordee. The width of urethral plate was measured both at its midpoint within the glans as described by Bush and Snodgrass [10] and also at the mid- point of urethral plate at the shaft of the penis after stretching the penis from both sides pressing it over the lower abdomen. However, the patients were grouped and analyzed according to the measurement of urethral plate width at the shaft because the shaft urethral plate is narrower and it is the part where most of the incision is spread over.

Measurements were taken at the beginning of the proce- dure, before creating glans wings or making the relaxing incision of the plate. We measured glans width at the widest part of the glans as described by Bush, Villanueva and Snodgrass [11]. A midline relaxing incision was made in the urethral plate as described by Snodgrass $[12,13]$.

The incised urethral plate was tubularized and glans wings were approximated with 6-0 vicryl suture. A dartos pedicle was transposed to the ventrum over neourethra in 38 patients, tunica virginals flap was used in 2 patients, and in 3 patients with distal penile hypospadias, skin and dartos were repaired as one layer over the urethral stitches. Dartos and penile skin was closed with 5-0 vicryl.

Surgeries were performed by multiple general paediatric surgeons and all were more than 45 years of age. It was hypothesized that narrow urethral plate width would adversely affect complication rate. Follow up period ranged from 6 months to 2.5 years (mean 692 days).

\section{Data Analysis}

Data were analyzed using windows-based software (SPSS22). The numerical data were expressed as mean with standard deviation ( \pm SD) and were compared by independent sample $t$ test or Mann-Whitney $U$ test. The categorical data were expressed as number and percentage and were compared by Chi-square test.

Primary outcome was the relation of urethral plate with the formation of complications and secondary outcomes were relation of other penile or perioperative factors such as glans width, duration of tourniquet, catheter and dressing, layers of repair and size of catheter with the development of complications such as UC fistula, meatal stenosis, wound infection, partial or complete wound disruption. 95\% confidence intervals $(\mathrm{Cl})$ was calculated for these values and level of significance was $5 \%$ (P 0.05).

\section{Ethical Considerations}

Informed written consent was obtained from parent of the patient. This study was approved by the ethical review board of Chittagong Medical College (ERB memo no-CMC/ PG/2017/355).

\section{Results}

Fifty-one patients were enrolled for the study initially. However, 3 patients had chordee of more than $30^{\circ}$ and found to have proximal hypospadias after release of chordee; and 5 patients had glandular or sub coronal hypospadias in whom TIP urethroplasty was not performed; and were excluded from the study. A total of 43 patients were finally included for analysis. Among them, 21 patients (48.8\%) were in Group $A$, with urethral plate width less than $8 \mathrm{~mm}$ and 22 patients $(51.2 \%)$ were in Group B with urethral plate width more than $8 \mathrm{~mm}$. The overall mean age was $6.69 \pm 0.52$ years with a range of 1-12 years. Patients with narrow urethral plate were younger than the patients with wide urethral plate (Table 1 , $p=0.0025)$.

Twenty-five (58\%) patients had distal hypospadias and 18 (42\%) patients had mid shaft hypospadias. Mid shaft hypo- 
Citation: Walid A, Sajid MM, Khastagir R, et al. (2021) Tubularized Incised Plate (TIP) Urethroplasty in Narrow V/S Wide Urethral Plate: A Comparative Study in a Developing Country Perspective . Arch of Pedia Surg 5(1):80-86

Table 1: Age distribution between groups and types of hypospadias patients $(n=43)$.

\begin{tabular}{|c|c|c|c|c|c|}
\hline \multirow[t]{2}{*}{ Groups } & \multicolumn{2}{|c|}{ Type of hypospadias } & \multicolumn{2}{|l|}{ Age in years } & \multirow[t]{2}{*}{ P value } \\
\hline & Mid penile & Distal penile & Mean ( \pm SD) & Range & \\
\hline Group A $(<8 \mathrm{~mm})(\mathrm{n}=21,48.8 \%)$ & 6 & 15 & $5.13 \pm 3.15$ & 01-12 & \multirow{3}{*}{0.0025} \\
\hline Group B $(>8 \mathrm{~mm})(\mathrm{n}=22,51.2 \%)$ & 12 & 10 & $8.19 \pm 3.04$ & $02-12$ & \\
\hline Total & $18(42 \%)$ & $25(58 \%)$ & $6.69 \pm 0.52$ & 01-12 & \\
\hline
\end{tabular}

Table 2: Penile characteristics between groups and types of hypospadias patients $(n=43)$.

\begin{tabular}{|c|c|c|c|c|c|c|}
\hline & \multicolumn{2}{|l|}{ Groups } & \multirow[t]{2}{*}{ P Value } & \multicolumn{2}{|l|}{ Type of Hypospadias } & \multirow[t]{2}{*}{ P Value } \\
\hline & Group A & Group B & & Distal Hypospadias & $\begin{array}{l}\text { Mid shaft } \\
\text { Hypospadias }\end{array}$ & \\
\hline Mean urethral plate width (mm) & $6.43 \pm 0.51$ & $8.14 \pm 0.35$ & $<0.001$ & $7.16 \pm 0.99$ & $7.50 \pm 0.92$ & 0.254 \\
\hline Glans Width (mm) & $15.95 \pm 2.69$ & $19.64 \pm 4.69$ & 0.003 & $17.60 \pm 3.88$ & $18.17 \pm 4.77$ & 0.67 \\
\hline \multicolumn{7}{|l|}{ Preoperative Testosterone } \\
\hline - Yes & 5 & 6 & & 7 & 4 & 0.668 \\
\hline - $\quad$ No & 16 & 16 & 0.795 & 18 & 14 & \\
\hline \multicolumn{7}{|l|}{ Glans Configuration } \\
\hline - $\quad$ Flat & $3(14.29 \%)$ & $0(0.00 \%)$ & & $1(4 \%)$ & $2(11.11 \%)$ & \\
\hline - Incompletely cleft & 17 (80.95\%) & 7 (31.82\%) & & $17(68 \%)$ & 7 (38.89\%) & \\
\hline - Cleft & $1(4.76 \%)$ & $15(68.18 \%)$ & $<0.001$ & $7(28 \%)$ & $9(50 \%)$ & 0.157 \\
\hline Penile length before degloving & $43 \pm 9.43$ & $35 \pm 7.46$ & 0.006 & $38.68 \pm 9.15$ & $39.83 \pm 9.49$ & 0.692 \\
\hline Penile length after degloving & $44 \pm 9.48$ & $36.77 \pm 7.48$ & 0.008 & $39.76 \pm 9.04$ & $41.06 \pm 9.59$ & 0.653 \\
\hline
\end{tabular}

Table 3: Comparison of Factors in Patients with Vs without UC Fistula.

\begin{tabular}{|l|l|l|l|}
\hline Factors & No UC Fistula & UC Fistula & $P$-value \\
\hline Mean Age, years & $6.85 \pm 3.38$ & $6.41 \pm 3.66$ & 0.71 \\
\hline Mean glans width, mm & $17.50 \pm 3.72$ & $18.47 \pm 5.14$ & 0.53 \\
\hline Mean shaft urethral plate width, mm & $7.32 \pm 0.95$ & $7.27 \pm 1.03$ & 0.87 \\
\hline Mean glans urethral plate width, mm & $7.57 \pm 0.84$ & $7.73 \pm 1.22$ & 0.61 \\
\hline Tourniquet duration, min & $39.54 \pm 13.57$ & $45.40 \pm 17.04$ & 0.26 \\
\hline Catheter size, Fr & $7.11 \pm 0.99$ & $6.93 \pm 0.96$ & 0.58 \\
\hline Repair layer, No. & $2.96 \pm 0.33$ & $3.0 \pm 0.37$ & 0.76 \\
\hline Dressing duration, days & $3.54 \pm 0.69$ & $3.33 \pm 0.70$ & 0.38 \\
\hline Catheter duration, days & $8.32 \pm 2.11$ & $7.73 \pm 3.49$ & 0.56 \\
\hline
\end{tabular}

spadias was more in Group B than Group A, however the difference was not significant $(p=0.084)$.

Both pre-incision urethral plate width and glans width were significantly more in group B than group A (Table 2). The mean pre-incision urethral plate width was $7.16 \pm 0.99$ for distal penile, $7.5 \pm 0.93$ for mid penile hypospadias with an overall mean of $7.3 \pm 0.96 \mathrm{~mm}$ for the entire cohort. The mean urethral plate width at the glans was $7.62 \pm 0.98 \mathrm{~mm}$ for the entire cohort. Mean glans width was $17.84 \pm 4.2$ in entire cohort, $15.95 \pm 2.69$ in group $A$ and $19.64 \pm 4.69 \mathrm{~mm}$ in group $B(p=0.003)$.

However, there was no significant difference of glans width between distal (mean $17.6 \pm 3.88 \mathrm{~mm}$ ) and mid shaft hypospadias (mean $18.17 \pm 4.77 \mathrm{~mm}$ ), $p=0.67$. Glans config- urations were significantly flatter in group $A$ and more clefted in group B. However, there was no significant difference in glans configuration between distal and midshaft hypospadias (Table 2).

Use of testosterone to enlarge the size of penis, penile length before and after degloving were also similar between groups and types of hypospadias (Table 2).

Complications developed in 18 (41.87\%) patients, 9 in each group. UC fistula developed in a total of 15 (34.88\%) patients ( 7 in group- $A$ and 8 in group-B, $P=0.55$ ) and meatal stenosis occurred in 7 (16.28\%) patients; 3 in group-A and 4 in group- $B$. There was also no significant difference in fistula rate between distal and mid shaft hypospadias (7/25 in distal and $8 / 18$ in mid penile hypospadias: $p=0.34)$. Among the pa- 
tients who developed UC fistula, 4 had meatal stenosis; however, there was no significant relation between UC fistula and meatal stenosis $(p=0.18)$.

Two patients developed early penile skin discoloration and both of them eventually developed UC fistula. No patient developed wound infection, glans dehiscence or complete disruption of wound.

Age at surgery correlated with glans size and pre-incision urethral plate width (Spearman's correlation $\mathrm{P}=0.019$ and 0.003 , respectively) but age was not different in patients with or without UC fistula (Figure 1 and Table 3).

There were no differences in glans size and pre-incision urethral plate width between patients with or without UC fistula (Table 3). Glans configuration, penile length before and after degloving and use of testosterone were not significantly different between patients with or without fistula $(P=0.63$, $0.59,0.62$ and 0.29 respectively). Tourniquet duration, size of stent used, layers of repair, duration of dressing and catheter also were not significantly different between patients with $\mathrm{v} / \mathrm{s}$ without fistula (Table 3).

These factors were not also significantly different between patients with or without other complications. Multiple logistic regression analysis also showed that none of the factors were significantly associated with UC fistula development or overall complications. Analysis with glans urethral plate width instead of shaft urethral plate width showed almost similar results and are not shown.

\section{Discussion}

The present study was carried out with an objective to observing whether urethral plate width in TIP urethroplasty had any impact on UC fistula. It was found that urethral plate width, and other parameters such as penile characteristics, duration of tourniquet, catheter and dressing, layers of repair were not significantly related to fistula development in TIP repair.

As has been suggested earlier, the result of hypospadias surgery depends on a constellation of many other factors such as surgical technique, delicate tissue handling, patient age, type of hypospadias defect and surgeon's experience [14].

Complications following TIP repair varies from center to center. Snodgrass reported only 6\% complication after repair of all types of hypospadias. [15] A recent meta-analysis of 49 studies showed that the overall complication rate following TIP repair is only $4-8.2 \%$ with more complication in parts of the world other than USA and Europe [16]. Braga, et al. reported in their literature review that median complication rate of TIP repair was $6.5 \%$, ranging from 0 to $23 \%$ and UC



Figure 1: Scatter diagram of correlation of age(years) with urethral plate width ( $\mathrm{mm}$ ). 
Citation: Walid A, Sajid MM, Khastagir R, et al. (2021) Tubularized Incised Plate (TIP) Urethroplasty in Narrow V/S Wide Urethral Plate: A Comparative Study in a Developing Country Perspective . Arch of Pedia Surg 5(1):80-86

fistula rate was $5.0 \%$ (mean $=5.9 \%$ ), ranging from 0 to $16 \%$ [17]. However, there are still reports of higher complication rates from the developing countries.

Chukwubuike, et al. reported a $31 \%$ complication rate for distal and mid shaft hypospadias in Nigeria [2]. Gupta, et al. reported a $21 \%$ complication rate with $13 \%$ UC fistula rate in their 100 patients of TIP repair in India [6]. Elbakry, et al. reported a $16.8 \%$ complication rate in their 172 patients of distal hypospadias who underwent TIP repair in Egypt [4]. Mammo, et al. (2018) showed $34.3 \%$ complication rate in their 128 patients of distal hypospadias repair in Ethiopia [5]. A report from Ghana (2020) showed $28 \%$ complication rate for TIP repair and another report from Nigeria (2017) showed $33.1 \%$ fistula rate $[3,18]$.

It is well accepted that type of hypospadias is an independent risk factor for fistula development with more proximal hypospadias having more fistulas. Although in this study fistula rate was more in midshaft than distal hypospadias, it was not statistically significant. There is no convincing evidence that penile anthropometry has clinical utility in distal hypospadias cases.

It was suggested that glans shape, urethral plate length, prepuce vascularization and penile size do not significantly affect the complication rate of TIP repair in distal hypospadias [19]. Bush, et al. reported that glans size is an independent risk factor for urethroplasty complications after hypospadias repair. Mean glans size of their patients were $15 \mathrm{~mm}$ (mean age of their patients was 1.5 years) and in this study it was $17.8 \mathrm{~mm}$ (mean age 6.69 years) [11].

On the other hand, Faasse, et al. reported that glans width was not a risk factor for complications after hypospadias repair [20]. Glans configuration was not associated with complications in this study and also in other studies [21-23]. Although, we had a higher rates of UC fistula and meatal stenosis, none of our patients developed glans dehiscence. Moreover, in 4 patients, meatal stenosis was associated with UC fistula; however, this occurred more in group-B patients who had wider urethral plate ( 3 in group-B vs 1 in group-A). These two observations suggest that probably our glans repair was too thick and tight to prevent dehiscence but predisposed for meatal stenosis and UC fistula formation.

Holland and Smith (2000) first reported a series of 48 distal TIP cases and urethral fistula developed in 6 patients with a urethral plate of less than $8 \mathrm{~mm}$ width $(P=0.001)$ suggesting that urethral fistula was exclusively associated with a maximal urethral plate width of less than $8 \mathrm{~mm}$ and cautioned that surgeons might consider alternative techniques to repair the subgroup with a narrow UP [23]. Subsequently, Sarhan, et al. also found that a pre-incision width $<8 \mathrm{~mm}$ correlated with increased urethroplasty complications in boys undergoing distal and midshaft TIP [24]. Aboutaleb (2014) reported similar finding in their 100 patients of distal hypospadias in whom 26 patients had less than $8 \mathrm{~mm}$ urethral plate [21].

However, Bush and Snodgrass (2017) later reported that pre-incision urethral plate width was not an independent risk factor for urethroplasty complications [15]. They measured the stretched width of the urethral plate at its widest part at the midpoint within the glans. However, the most extent of neourethra is spread over shaft urethral plate which is slightly narrower than glans urethral plate and we believe, there should be more concern about the narrower part rather than the widest part while analyzing the effect of width on complications. We measured urethral plate at both sites, however, the difference between the two measurements was minimum and both had almost similar interpretations. Earlier, a multicenter study of 159 prepubertal boys who underwent TIP repair for primary distal hypospadias, in whom urethral plate was less than $8 \mathrm{~mm}$ in 30 cases, conducted by Nguyen and Snodgrass, et al. found that only $3(2 \%)$ patients developed UC fistula [22].

It has been suggested by Snodgrass that midline incision of the urethral plate should be enough to create a neourethra with adequate width around catheters so that the urethral plate makes a tension free anastomosis. One of the reasons behind the widespread use of TIP repair is that Snodgrass suggested that the incised urethra heals by re-epithelialisation rather than scarring which was supported by other studies [25]. Tan, et al. also showed that, in rabbit, the neourethra repaired by TIP was practically resumed to normal anatomy with less scarring but there was increased activity of fibroblasts [26]. On the other hand, a recent case report showed that histological analysis of the incised urethral plate revealed absence of smooth muscles, vessels and elastin fibers within the area of the incised plate in a patient who developed meatal stenosis after TIP repair [27]. Further studies on histologic analysis of urethral plate is necessary to confirm these findings.

The mean age of patients in this study was 6.69 years which is far beyond the current recommended age for hypospadias repair. This is also a reality of developing world where many patients present late. Although, there was significant difference between groups with regards to age; age was not related with outcome in this study.

There are also conflicting reports of impact of age on outcome [28-29]. Only 4 (9.3\%) patients were within recommended age of 2 years and one of them developed UC fistula who developed soaked dressing and peri catheter leakage very early suggesting technical failure rather than anatomy of the defect. Perlmutter, et al. reported better outcome in early surgery, mean age of their patients without complications was 18.5 months compared with 26.5 months for patients developing complications [28].

Age was a significant risk factors for UC fistula after hypospadias repair in Indonesia and about $60 \%$ of their patients were more than 4 years old [30]. However, Weber, et al. did not find evidence to support recommendations concerning the ideal age for hypospadias repair [31]. Types and duration of catheter or stent, suturing types and technique, type and duration of dressing produced variable results and none was an independent risk factor. These were not also related to UC fistula in this study. Although some studies reported good outcome with different types of additional layers, comparative studies did not show benefit of one over another. 
Citation: Walid A, Sajid MM, Khastagir R, et al. (2021) Tubularized Incised Plate (TIP) Urethroplasty in Narrow V/S Wide Urethral Plate: A Comparative Study in a Developing Country Perspective . Arch of Pedia Surg 5(1):80-86

The most commonly practiced alternate microsurgical technique used for distal and mid shaft hypospadias is peri meatal based flap (Mathieu) procedure. One important disadvantage of this technique is that the meatus usually become horizontal and rounded which is less acceptable than the slit-like meatus of the TIP technique. Now a days, Mathieu procedure has become less popular than TIP. In a prospective randomized study, Khalil, et al. compared a modification of Mathieu procedure called Mathieu incised-plate (Mathieu IP) procedure with TIP procedure and reported less meatal stenosis and UC fistula with Mathieu IP [7].

A recent meta-analysis that compared TIP and Mathieu procedure suggested that they were equivalent in terms of fistula, wound dehiscence, and flap necrosis but there was a significantly lower rate of meatal stenosis with Mathieu rather than with TIP. They commented that the modified Mathieu technique and a running suture for urethroplasty could be related to a lower rate of meatal stenosis [8].

Our study has some observations which are pertinent to developing countries. While developed world has reduced the complications following hypospadias repair, it is evident that developing countries, where most hypospadias surgeries are still done by general paediatric surgeons, still have unacceptable complication rates. Surgeries were done by multiple paediatric surgeons in this study, who, although experienced, are not dedicated paediatric urologists. Moreover, most of the surgeons did not use loupe during hypospadias surgery, which is a very essential component for successful outcome of hypospadias repair. Meticulous tissue dissection and proper haemostasis have been said to be the key factors for best outcome in hypospadias surgery and the application of these varied greatly among surgeons.

Microsurgical techniques allow surgeons to clearly observe the bole and branch of blood vessels and damage of nutrient vessel can be decreased, tissue dissection can be accurate, haemorrhage and hematoma can be decreased, and sutures can be properly placed without errors [32]. For better results with hypospadias surgeries, emphasis should be given on issues such as improving skills, facilities, use of delicate instruments, use of loupes, and need for dedicated hypospadias surgeons.

These things are not still practiced in many developing countries. Braga, et al. in their literature review, found that studies with a small sample size $(n<30)$ reported more complications (> 20\%) in comparison to studies involving large number of patients. They suggested that surgeon experience and high volume of cases may contribute to reduce the number of complications in any series [17]. It also alludes to the fact that hypospadias surgeries are better performed by paediatric urologists and developing countries should give emphasis on developing independent paediatric urology departments.

Our study has several limitations. Sample size was small and the penile characteristics and outcomes were assessed by single observant who was also the principal author of the study. The surgeries were performed by multiple surgeons who had different level of expertise and dedication for hypo- spadias surgeries. This also has an important negative effect on analyzing the influence of a patient's characteristic on any outcome. Further studies with larger sample size and longer follow up is necessary to confirm the effect of width of the shaft urethral plate on outcome of TIP procedure.

\section{Conclusion}

This study showed that there was no significant difference in the occurrence of complications following TIP repair in patients with narrow versus wide urethral plate. Complications were higher than many other studies but consistent with some reports from developing countries. Improvement of surgical skill and establishment of dedicated paediatric urology centres are necessary in the developing world to attain good surgical outcomes which has already been availed by the developed world.

\section{Conflicts of Interest}

None

\section{Funding}

None

\section{Ethics Approval}

Informed written consent was obtained from parent of the patient. This study was approved by the ethical review board of Chittagong Medical College (ERB memo no-CMC/ $P G / 2017 / 355)$. This study is a part of thesis of the principal author under Bangabandhu Sheikh Mujib Medical University, Bangladesh.

\section{Acknowledgements}

The authors like to acknowledge Dr. Farid Uddin Ahmed, $\mathrm{MPH}$ for his support in statistical analysis.

\section{References}

1. Lorenzo AJ, Snodgrass WT (2002) Regular dilatation is unnecessary after tubularized incised-plate hypospadias repair. BJU Int 89: 94-97.

2. Chukwubuike KE, Ekenze SO, Ezomike UO, et al. (2019) Assessment of the effect of urethral plate width on outcome of hypospadias repair. J Pediatr Urol 15: 627e1-627e6.

3. Appeadu-mensah W, Adwo A, Hesse J, et al. (2015) Complications of hypospadias surgery: Experience in a tertiary hospital of a developing country Afr J Paediatr Surg 12: 211-216.

4. Elbakry A, Hegazy M, Matar A, et al. (2016) Tubularised incised-plate versus tubularisation of an intact and laterally augmented plate for hypospadias repair: A prospective randomised study. Arab J Urol 14: 163-170.

5. Tihitena NM, Samuel AN, Teamir N, et al. (2018) Hanna hypospadias repair in ethiopia: A five year review. Ethiop J Heal Sci 28: 735-740.

6. Gupta A, Gupta R, Srivastav P, et al. (2017) Comparison of interrupted- and continuous-suture urethroplasty in tubularised incised-plate hypospadias repair: A prospective study. Arab J Urol 15: 312-318.

7. Khalil M, Gharib T, El-shaer W, et al. (2017) Mathieu technique 
Citation: Walid A, Sajid MM, Khastagir R, et al. (2021) Tubularized Incised Plate (TIP) Urethroplasty in Narrow V/S Wide Urethral Plate: A Comparative Study in a Developing Country Perspective . Arch of Pedia Surg 5(1):80-86

with incision of the urethral plate versus standard tubularised incised-plate urethroplasty in primary repair of distal hypospadias: A prospective randomised study. Arab J Urol 15: 242-247.

8. Zhang Y, Shen Z, Zhou X, et al. (2020) Comparison of meatal-based flap(mathieu)and tubularized incised-plate (tip) urethroplasties for primary distal hypospadias: A systematic review and meta-analysis. J Pediatr Surg 55: 2718-2727.

9. Winberg H, Arnbjörnsson E, Anderberg M, et al. (2019) Postoperative outcomes in distal hypospadias: A meta-analysis of the Mathieu and tubularized incised plate repair methods for development of urethrocutaneous fistula and urethral stricture. Pediatr Surg Int 35: 1301-1308.

10. Bush NC, Snodgrass W (2017) Pre-incision urethral plate width does not impact short-term tubularized incised plate urethroplasty outcomes. J Pediatr Urol 13: 625.e1-625.e6.

11. Bush NC, Villanueva C, Snodgrass W, et al. (2015) Glans size is an independent risk factor for urethroplasty complications after hypospadias repair. J Pediatr Urol 11: 355 e1-355 e5.

12. Snodgrass WT (2005) Surgical atlas snodgrass technique for hypospadias repair. BJU Int 95: 683-693.

13. Snodgrass W (1994) Tubularized, incised plate urethroplasty for distal hypospadias. J Urol 151: 464-465.

14. Snodgrass WT (2002) Tubularized incised plate (tip) hypospadias repair. Urol Clin North Am 29: 285-290.

15. Bush NC, Snodgrass W (2017) Pre-incision urethral plate width does not impact short-term tubularized incised plate urethroplasty outcomes. J Pediatr Urol 13: 625.e1-625.e6.

16. Pfistermuller KLM, McArdle AJ, Cuckow PM et al. (2015) Meta-analysis of complication rates of the tubularized incised plate (TIP) repair. J Pediatr Urol 11: 54-59.

17. Braga LHP, Lorenzo AJ, Salle JLP et al. (2008) Tubularized incised plate urethroplasty for distal hypospadias: A literature review. Indian J Urol 24: 219-225.

18. Ogundoyin O, Olulana D, Lawal T, et al. (2017) Management of hypospadias in a resource-poor setting: The ibadan experience. Niger J Plast Surg 13: 40-44.

19. Da Silva EA, Lobountchenko T, Marun MN, et al. (2014) Role of penile biometric characteristics on surgical outcome of hypospadias repair. Pediatr Surg Int 30: 339-344.
20. Faasse MA, Johnson EK, Bowen DK, et al. (2016) Is glans penis width a risk factor for complications after hypospadias repair? J Pediatr Urol 12: 202.e1-202.e5.

21. Aboutaleb H (2014) Role of the urethral plate characters in the success of tubularized incised plate urethroplasty. Indian J Plast Surg 47: 227-231.

22. Nguyen MT, Snodgrass WT (2004) Effect of urethral plate characteristics on tubularized incised plate urethroplasty. J Urol 171: 1260-1262.

23. Holland AJA, Smith GHH (2000) Effect of the depth and width of the urethral plate on tubularized incised plate urethroplasty. J Urol 2000 164: 489-491.

24. Sarhan O, Saad M, Helmy T, et al. (2009) Effect of suturing technique and urethral plate characteristics on complication rate following hypospadias repair: A prospective randomized study. J Urol 182: 682-686.

25. Genç CT, Güns C, Türkdog` P, et al. (2002) Histopathological evaluation of the urethra after the snodgrass operation : An experimental study in rabbits. BJU Int 90: 950-952.

26. Tan X, Long C, Zhang D, et al. (2018) Histological and biochemical evaluation of urethral scar following three different hypospadias repairs : An experimental study in rabbits Comparative Study 28: 420-425.

27. Abbas TO, Charles A, Ali M, et al. (2020) Long-term fate of the incised urethral plate in snodgrass procedure : A real concern does exist. Urol Case Reports 101216.

28. Perlmutter AE, Morabito R, Tarry WF, et al. (2006) Impact of patient age on distal hypospadias repair: A surgical perspective. Urology 68: 648-651.

29. Levy M, Gor RA, Vanni AJ, et al. (2017) The impact of age on urethroplasty success. Urology 107: 232-238.

30. Duarsa GWK, Tirtayasa PMW, Daryanto B, et al. (2020) Risk factors for urethrocutaneous fistula following hypospadias repair surgery in indonesia. J Pediatr Urol 16: 317.e1-317.e6.

31. Weber DM, Schonbucher VB, Gobet R, et al. (2009) Is there an ideal age for hypospadias repair? A pilot study. J Pediatr Urol 5: 345-350.

32. Gu Xinquan, Li Yang, Zhang Ming, et al. (2011) Selection of surgical procedures and microsurgical techniques for one-stage hypospadias repair. Conferences.

DOI: $10.36959 / 472 / 360$

Copyright: (c) 2021 Walid A, et al. This is an open-access article distributed under the terms of the Creative Commons Attribution License, which permits unrestricted use, distribution, and reproduction in any medium, provided the original author and source are credited. 